\title{
Exsudato Radicular de Imazapyr Aplicado sobre Mudas De Diferentes Clones de Eucalipto ${ }^{1}$
}

\author{
Radicular Exsudate of Imazapyr Applied on Seedlings of Different Eucalypt Clones
}

\author{
SOUZA, G.V.R. ${ }^{2}$, FERREIRA, L.R. ${ }^{3}$, SEDIYAMA, C.S. ${ }^{4}$, SILVA, C.M.M. ${ }^{5}$, TUFFI SANTOS, L.D. ${ }^{6}$ \\ e VIANA, R.G. ${ }^{6}$
}

\begin{abstract}
RESUMO - Na renovação de eucaliptais, após o corte das árvores, faz-se necessária a eliminação da rebrota, que interfere no desenvolvimento inicial das novas mudas. Essa eliminação pode ser feita por meio da aplicação de alguns herbicidas via caule. Um dos herbicidas utilizados é o imazapyr, que, de acordo com trabalhos realizados na UFV, é capaz de exsudar via sistema radicular. Nesse caso, surgem dúvidas se a exsudação do produto poderá interferir no desenvolvimento das novas mudas; se a capacidade de exsudação é a mesma em todos os clones de eucalipto; em qual dose de imazapyr esse problema é mais grave; e em qual intensidade o herbicida exsudado interferirá no crescimento das plantas. Este trabalho avaliou se os sistemas radiculares dos clones apresentam diferentes intensidades de exsudação de imazapyr, bem como o efeito das doses aplicadas na concentração do herbicida no perfil do solo e sua influência na cultura subseqüente ao eucalipto. Foi verificado decréscimo de matéria seca nas plantas de sorgo, quando comparadas com as testemunhas, tanto na camada de 0-15 cm como na de 15-30 cm, evidenciando a exsudação do imazapyr via sistema radicular pelos quatro clones estudados. Os efeitos tóxicos dos exsudados radiculares foram observados no solo em todo o volume alcançado pelo sistema radicular do eucalipto. À medida que se aumentaram as doses de imazapyr, os sintomas de toxicidade no sorgo foram mais acentuados. A exsudação do imazapyr pelos eucaliptos foi semelhante nas duas profundidades analisadas.
\end{abstract}

Palavras-chave: eliminação da rebrota, herbicida, replantio.

\begin{abstract}
In the renewal of eucalypt crops, after tree harvesting, it is necessary to eliminate the sprouts that interfere with the initial development of the new stands. This elimination can be made by applying some herbicides on the shoots. One of the herbicides used is imazapyr, which, according to preliminary works carried out at the Universidade Federal de Viçosa, is capable to exsudate through the root system. In this case, questions arise concerning the exsudate ability to interfere in the development of the new plants; whether this capacity is the same for all eucalypt clones; at which imazapyr dose this problem is more serious; and the intensity at which the herbicide exsudate will interfere with the growth of the new stands. This work evaluated whether the root systems of different clones present different imazapyr exsudation intensities and the effect of the applied doses on herbicide concentration in the soil profile and its influence in subsequent crops. A dry mater decrease was verified in the sorghum plants when compared to the checks, in both 0-15 and 15-30 cm soil layers, evidencing imazapyr exsudation through the root system of the four clones analyzed. The toxic effect of the exsudates was observed in the entire soil volume reached by the eucalypt root system. Increased imazapyr doses increased the toxicity symptoms in sorghum imazapyr exsudation by all eucalypt clones was similar at the two depths analyzed.
\end{abstract}

Keywords: sprout elimination, herbicide, replanting.

Recebido para publicação em 5.9.2005 e na forma revisada em 24.2.2006.

2 Mestrando em Fitotecnia, Dep. de Fitotecnia, Universidade Federal de Viçosa - DFT/UFV, 36570-000 Viçosa-MG; ${ }^{3}$ Professor Adjunto, DFT/UFV; ${ }^{4}$ Professor Titular, DFT/UFV; ${ }^{5}$ Doutorando pela Universidade Estadual do Norte Fluminense - UENF, 28013-600 Campos dos Goytacazes-RJ; ${ }^{6}$ Doutorando em Fitotecnia, DFT/UFV. 


\section{INTRODUÇÃO}

O setor florestal destaca-se no agronegócio brasileiro, perdendo apenas para o complexo soja. Hoje, o Brasil possui uma das maiores áreas plantadas de eucalipto do mundo (mais de 3 milhões de hectares), alcançando o maior índice médio de produtividade $\left(40 \mathrm{~m}^{3}\right.$ por hectare ao ano), segundo o Ministério da Ciência e Tecnologia (Brasil, 2005).

O aumento da produção por área e a diminuição dos custos de produção conferem ao setor alta competitividade no mercado mundial, tendo em vista o curto espaço de tempo para obtenção de madeira em comparação com as florestas de clima temperado. Em virtude da grande demanda para exportação e atendimento do mercado interno por parte das indústrias de papel e celulose, bem como das de carvão vegetal e de serrarias (visando à fabricação de móveis) (SBS, 2003), há necessidade de manutenção de grandes áreas reflorestadas a baixo custo, sem o comprometimento da produção florestal, da qualidade da madeira e do ambiente (Silva, 1993).

Dentre as práticas silviculturais está o manejo da rebrota, que, no caso de plantios comerciais destinados à indústria de celulose e energia, muitas vezes apresenta um período de cultivo de apenas um ciclo. A renovação precoce do eucaliptal deve-se à possibilidade de substituição por clones mais adaptados às diferentes regiões produtoras, provenientes dos programas de melhoramento, o que reflete em ganhos de produtividade e qualidade do produto final. Por sua vez, dependendo do uso do eucalipto e do nível tecnológico de produção, o manejo da rebrota pode conduzir às brotações das touças em cada ciclo, permitindo um mínimo de três explorações econômicas (Silva, 1983). Na renovação dos eucaliptais, por meio do plantio de novas mudas, torna-se indesejável a presença de brotações das touças, recorrendo-se ao uso de herbicidas para controlá-las. Parte do herbicida, aplicado via pulverizações foliares, pode ter como destino final o solo, seja pelo contato direto da calda pulverizada ou pela exsudação radicular das plantas tratadas.

Alguns herbicidas são capazes de ser exsudados pelo sistema radicular de plantas daninhas e de culturas agrícolas, como o nicosulfuron (Gubbiga et al., 1996), o 2,4-D (Fites et al., 1964), o glyphosate (Coupland \& Caseley, 1979) e o imazapyr (Silva et al., 2004b), podendo vir a causar danos à cultura subseqüente.

O imazapyr, produto pertencente ao grupo químico das imidazolinonas (ácido 2-(4isopropil-4-metil-5-oxo-2-imidazolina-2-ilo) nicotínico), é um herbicida de amplo espectro de utilização: manutenção de ferrovias, oleodutos, rodovias (acostamento), pátios de indústrias e escolas, aeroportos, cemitérios, linhas de transmissão, controle de plantas daninhas em áreas agrícolas e controle da rebrota em áreas florestais (Rodrigues \& Almeida, 2005). Segundo Tucker et al. (1994), seu mecanismo de ação caracteriza-se pela inibição da síntese de acetohidróxido sintase (AHAS), enzima encontrada somente em espécies vegetais, comum no processo de biossintese de três aminoácidos alifáticos essenciais: valina, leucina e isoleucina. Uma vez que pode atuar sobre o "pool" de aminoácidos e a fração protéica, o imazapyr desorganiza a síntese de proteínas, por alterar a taxa de giro protéico (Shaner \& Reiner, 1986; Shaner, 1989). Essa inibição irá interromper a síntese de proteínas, que, por conseguinte, interfere na síntese de DNA e no crescimento celular, o que acarretará a morte das regiões meristemáticas (Rodrigues \& Almeida, 2005).

A exsudação radicular do imazapyr por E. grandis e seu efeito em mudas da mesma espécie foram verificadas por Silva et al. (2004b). Entretanto, não se sabe se a exsudação é comum para os diferentes clones de eucalipto, tampouco sobre sua distribuição no perfil do solo.

Este trabalho teve como objetivo avaliar se o sistema radicular dos clones apresenta diferentes intensidades de exsudação de imazapyr, bem como o efeito das doses aplicadas na concentração do herbicida no perfil do solo e sua influência na cultura subseqüente ao eucalipto.

\section{MATERIAL E MÉTODOS}

Foram utilizadas mudas de três clones (clones 1, 2 e 3) de eucalipto oriundos do cruzamento entre as espécies Eucalyptus grandis e E. urophylla ("urograndis") e de um 
clone (clone 4) de E. grandis, fornecidas pela CENIBRA S.A., com 25 a $30 \mathrm{~cm}$ de altura. As mudas foram retiradas dos tubetes e, imediatamente, transplantadas para vasos de $18 \mathrm{~L}$, revestidos com sacos plásticos, perfazendo uma planta por vaso. Os vasos foram previamente preenchidos com solo, cujas características físicas e químicas encontram-se na Tabela 1, sendo a adubação realizada de acordo com as exigências da cultura. Após o transplantio, os vasos foram mantidos no limpo e as plantas, irrigadas diariamente, de forma a manter a umidade próxima da capacidade de campo.

O delineamento experimental utilizado foi o de blocos casualizados, com cinco repetições, instalado em fatorial $4 \times 5$ (quatro clones $\mathrm{x}$ cinco doses de imazapyr), sendo cada vaso correspondente a uma parcela experimental.

A aplicação do imazapyr foi feita depois de transcorridos sete meses do transplantio das mudas nos vasos, utilizando-se um pulverizador costal pressurizado a $\mathrm{CO}_{2}$, trabalhando a $300 \mathrm{kPa}$ de pressão e com volume de calda de $200 \mathrm{~L} \mathrm{ha}^{-1}$, equipado com barra contendo dois bicos TT 110 02. As doses aplicadas foram de $0 ; 0,93 ; 0,188 ; 0,375$; e $0,750 \mathrm{~g} \mathrm{ha}^{-1}$ do i.a. (correspondendo a $0 ; 0,375 ; 0,75 ; 1,5$; e 3,0 L ha-1 de Chopper NA, respectivamente). No momento da aplicação, os recipientes foram protegidos com dupla camada de filme plástico, com o intuito de evitar o contato da calda herbicida com o solo e, conseqüentemente, a sua contaminação com o herbicida. A pulverização atingiu toda a parte aérea das plantas de eucalipto.
Trinta dias após aplicação do imazapyr, avaliou-se a parte aérea do eucalipto quanto aos sintomas de fitotoxicidade causados pelo herbicida. Em seguida, a parte aérea das plantas de eucalipto foi cortada e acondicionada, individualmente, em sacos de papel e colocada para secar em estufa com circulação de ar a $72{ }^{\circ} \mathrm{C} \mathrm{r} 3$, até atingir peso constante (aproximadamente 72 horas), para determinação da matéria seca.

Posteriormente ao corte das plantas de eucalipto, os vasos (latas) foram colocados na posição horizontal e seus lados superiores recortados, para permitir a semeadura do sorgo no perfil do solo. Após a germinação e emergência das plântulas de sorgo, foi feito um desbaste, deixando-se 10 plantas na porção equivalente à camada de $0 \mathrm{a} 15 \mathrm{~cm}$ e 10 na camada de 15 a $30 \mathrm{~cm}$. Essas plantas foram adubadas (formulação 8-28-16) e irrigadas diariamente. Decorridos 25 dias, a contar da data da semeadura, as plantas de sorgo tiveram a parte aérea cortada, sendo estas colocadas para secar em estufa com circulação forçada de ar a $72{ }^{\circ} \mathrm{C} r 3$ até atingirem peso constante (aproximadamente $72 \mathrm{~h}$ ), para determinação da matéria seca.

A presença do herbicida exsudado foi avaliada por meio do aspecto das plantas de sorgo após a germinação (sintomas visualmente identificados) e da produção de matéria seca, comparados nas duas profundidades no vaso e com as plantas testemunhas (dose zero de imazapyr).

Tabela 1 - Análises química e física do solo

\begin{tabular}{|c|c|c|c|c|c|c|}
\hline \multicolumn{7}{|c|}{ Análise Química } \\
\hline \multirow{2}{*}{$\begin{array}{c}\mathrm{pH} \\
\left(\mathrm{CaCl}_{2}\right)\end{array}$} & $\mathrm{P}$ & $\mathrm{K}$ & $\mathrm{Ca}$ & $\mathrm{Mg}$ & $\mathrm{Al}$ & $\mathrm{H}+\mathrm{Al}$ \\
\hline & \multicolumn{3}{|c|}{$\left(\mathrm{mg} \mathrm{dm}^{-3}\right)$} & \multicolumn{3}{|c|}{$\left(\mathrm{cmol}_{\mathrm{c}} \mathrm{dm}^{-3}\right)$} \\
\hline 4,2 & 1,4 & 23,0 & 0,54 & 0,17 & 1,3 & 4,11 \\
\hline \multicolumn{7}{|c|}{ Análise Física } \\
\hline \multicolumn{7}{|c|}{$\left(\right.$ dag kg $\left.^{-1}\right)$} \\
\hline \multicolumn{4}{|c|}{ Areia } & \multicolumn{3}{|c|}{36,4} \\
\hline \multicolumn{4}{|c|}{ Silte } & \multicolumn{3}{|c|}{5,3} \\
\hline \multicolumn{4}{|c|}{ Argila } & \multicolumn{3}{|c|}{58,3} \\
\hline \multicolumn{7}{|c|}{ Classe textural: argilosa } \\
\hline
\end{tabular}

Análises realizadas nos Laboratórios de Análises Físicas e Químicas de Solo do Departamento de Solos da UFV. 
Os dados foram submetidos à análise de variância, utilizando-se 5\% de significância. Para matéria seca da parte aérea das plantas de sorgo e eucalipto, foram ajustadas regressões por meio do programa computacional SANEST (Zonta \& Machado, 1984).

\section{RESULTADOS E DISCUSSÃO}

As análises de variâncias dos dados da matéria seca da parte aérea do eucalipto, assim como da parte aérea do sorgo, nas profundidades de 0-15 e 15-30 cm de solo nos vasos, indicaram efeito significativo de clones e de doses. Foi observado, também, efeito da interação clones $\mathrm{x}$ doses na matéria seca da parte aérea do sorgo semeado na profundidade de $15-30 \mathrm{~cm}$. O coeficiente de variação foi de $10,04 \%$ para a matéria seca do eucalipto e variou de 24,49 a $24,12 \%$ para a matéria seca da parte aérea do sorgo semeado de 0 a $15 \mathrm{~cm}$ e de 15 a $30 \mathrm{~cm}$, respectivamente. Com relação às avaliações visuais do aspecto das plantas de eucalipto (coeficiente de variação de $23,28 \%$ ) e das de sorgo, nas duas profundidades (coeficientes de variação de 27,70 e $27,14 \%$, respectivamente), observou-se efeito significativo de doses e de clones nessas três variáveis analisadas. Não foi observada interação clone $\mathrm{x}$ dose em qualquer variável, indicando comportamento semelhante na exsudação de imazapyr pelos quatro clones, em resposta à aplicação desse herbicida.

Em todos os clones de eucalipto (Figura 1) ocorreu decréscimo significativo na matéria seca à medida que a dose do herbicida aumentou. Mesmo sob a menor dose utilizada de imazapyr $\left(0,93 \mathrm{~g} \mathrm{ha}^{-1}\right.$ i.a. $)$ não se verificou rebrota nos quatro clones avaliados, ao passo

\section{CLONE 1}
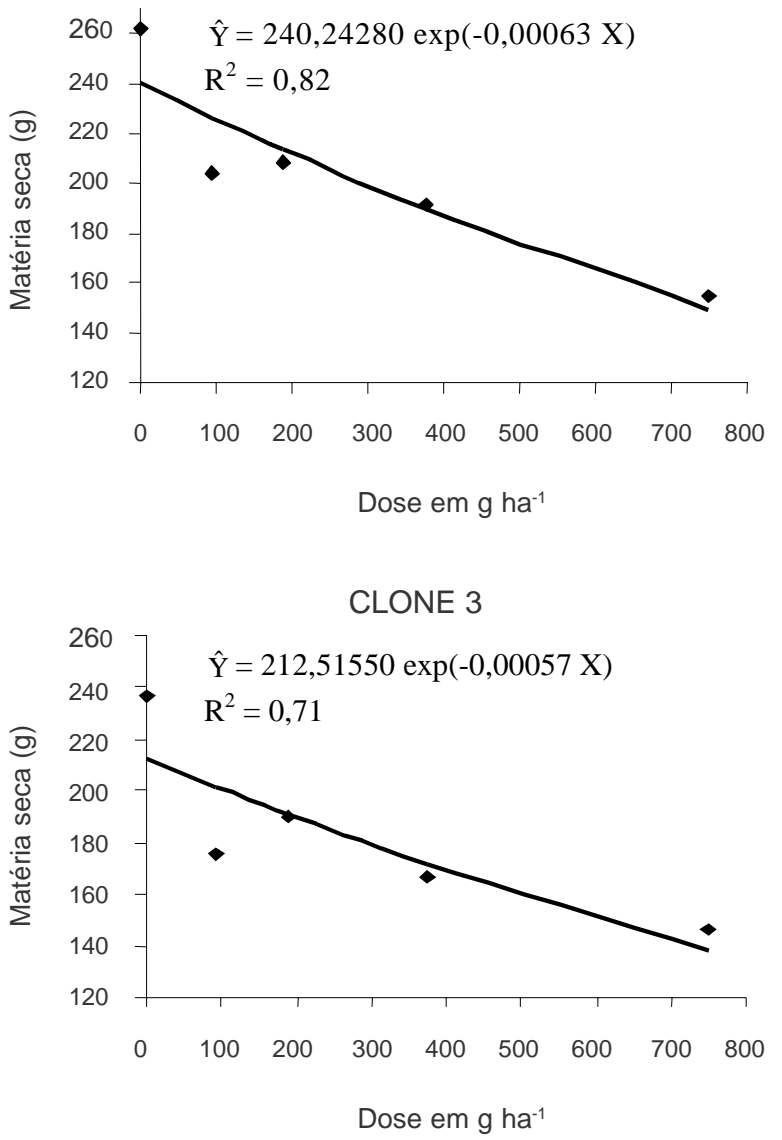

CLONE 2
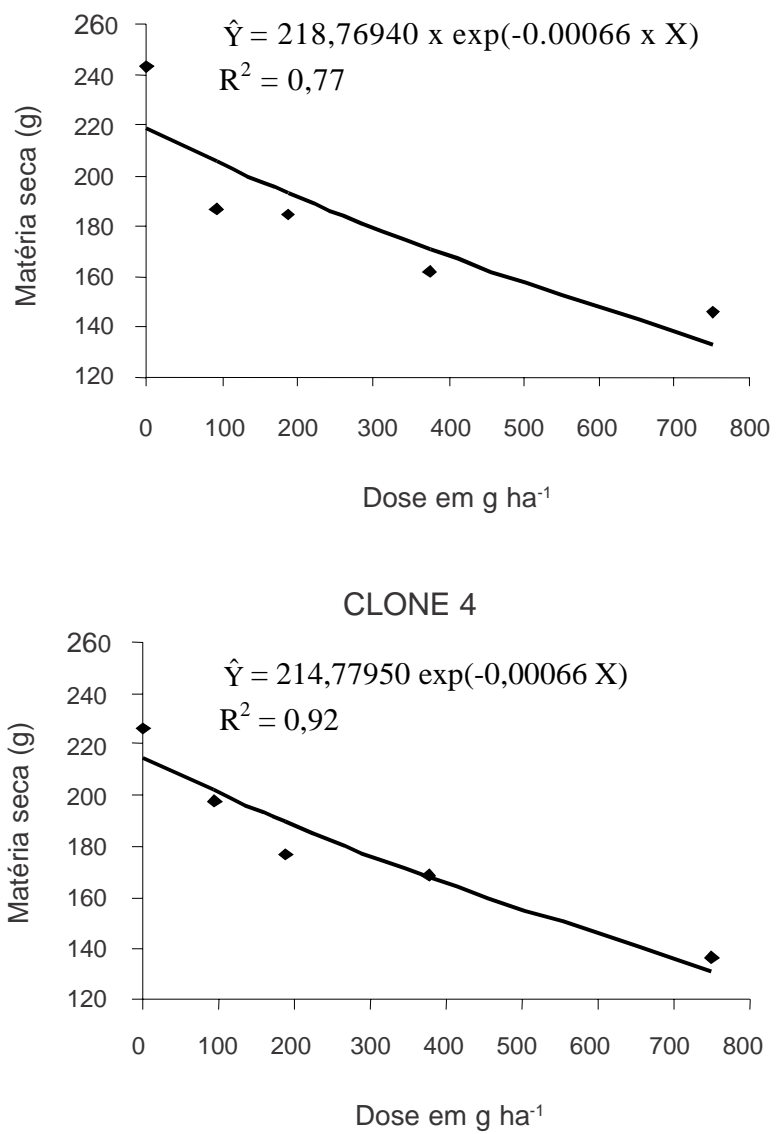

Figura 1 - Matéria seca das plantas de diferentes clones de eucalipto aos oito meses após o transplantio, 30 dias após aplicação de diferentes doses de imazapyr. 
que as plantas que não receberam aplicação de imazapyr apresentaram várias brotações em seus caules anteriormente cortados. Segundo Silva et al. (2004a), os clones apresentaram comportamento distinto entre si quanto à presença de imazapyr em solução do solo, indicando que para controle de rebrota as doses também podem ser diferenciadas, de acordo com o clone cultivado.

Nas Figuras 2 e 3, observa-se que houve decréscimo no acúmulo de matéria seca nas plantas de sorgo com o aumento das doses de imazapyr aplicado sobre as plantas de eucalipto, tanto na camada de 0 a 15 como na de 15 a $30 \mathrm{~cm}$, evidenciando a exsudação do imazapyr via sistema radicular pelos quatro clones analisados. Os efeitos tóxicos dos

\section{CLONE 1}

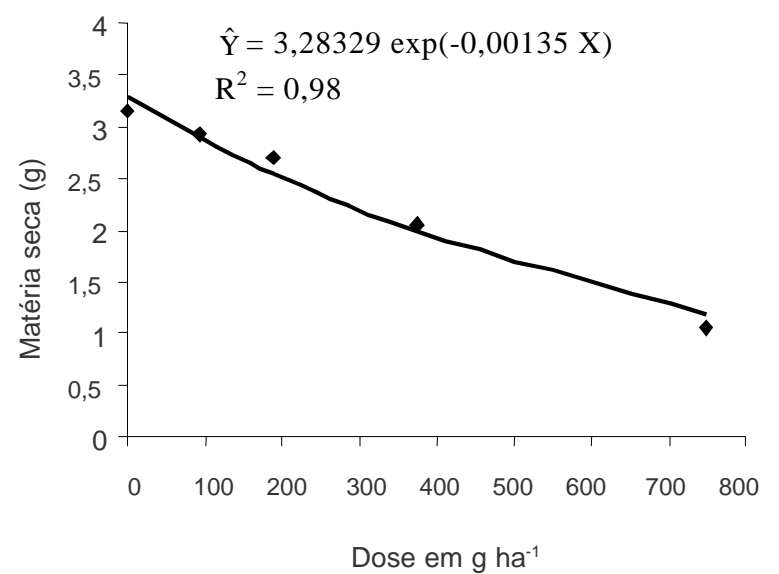

\section{CLONE 3}

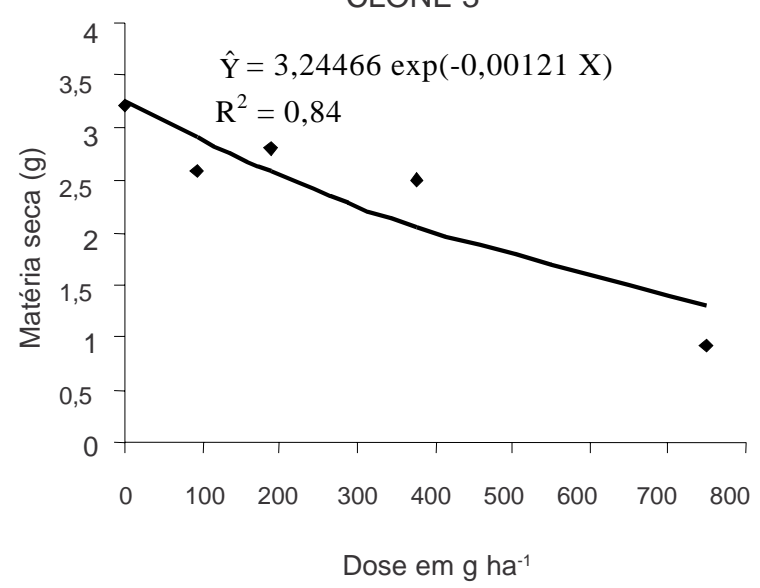

exsudados radiculares foram observados em toda a área coberta pelo sistema radicular do eucalipto, não sendo observada diferença entre as plantas de sorgo cultivadas nas duas camadas (0 a 15 e 15 a $30 \mathrm{~cm}$ ). Verificou-se que, à medida que se elevaram as doses do herbicida, aplicadas sobre plantas de eucalipto, o sorgo apresentou sintomas mais severos de toxicidade na parte aérea, indicando maior exsudação radicular de imazapyr e/ou de seus metabólitos no solo, fato também observado por Silva et al. (2004a). Segundo esses mesmos autores, o herbicida imazapyr aplicado sobre plantas de E. grandis foi exsudado, e/ou seus metabólitos, em concentrações capazes de afetar o crescimento de plantas da mesma espécie.
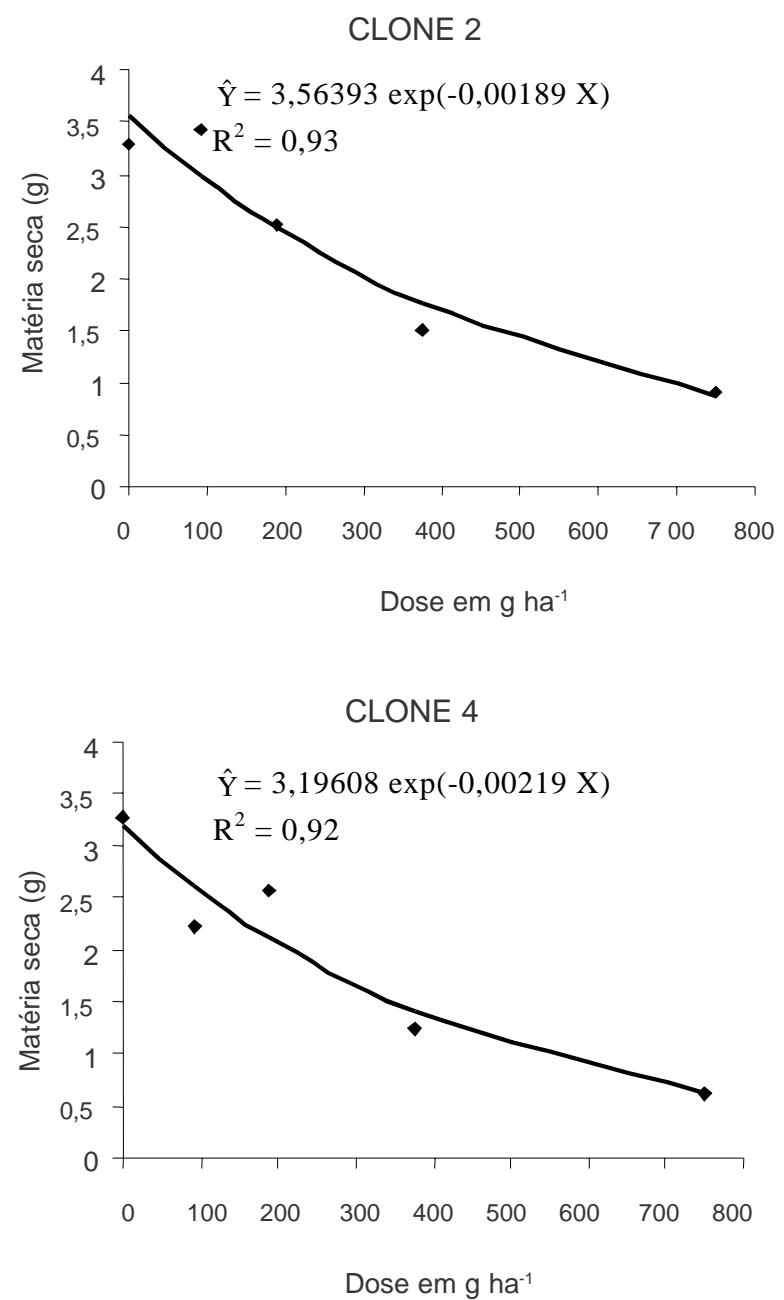

Figura 2 - Matéria seca da parte aérea de plantas de sorgo aos 25 dias após semeadura na porção equivalente à profundidade de 0 a $15 \mathrm{~cm}$, nos vasos com plantas de eucalipto que receberam aplicação foliar de doses de imazapyr aos sete meses após o plantio e foram cortadas 30 dias depois da aplicação do herbicida. 
CLONE 1

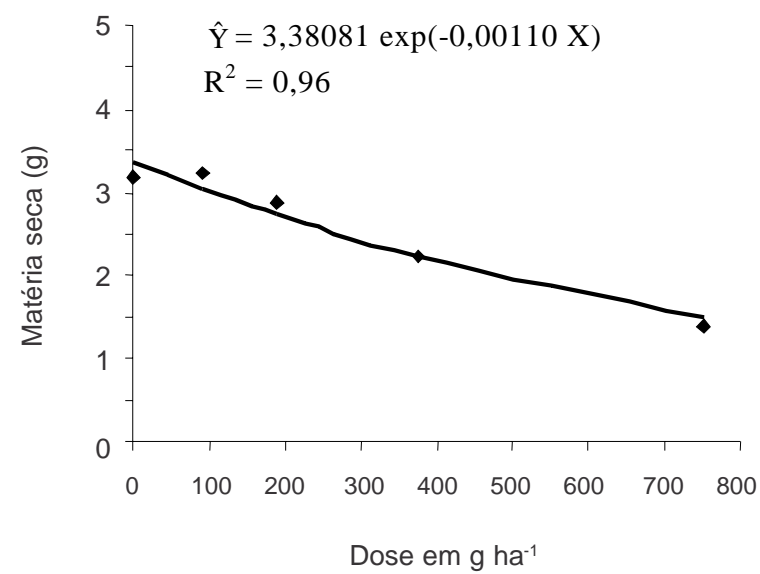

CLONE 3

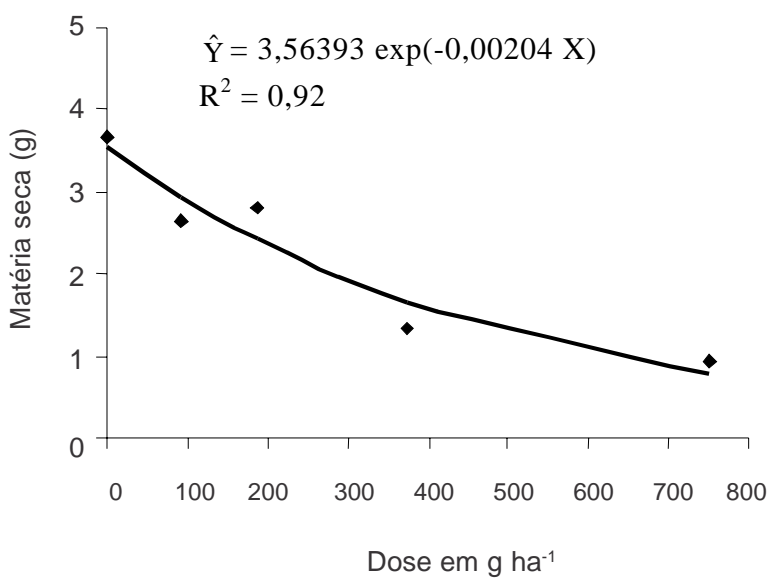

CLONE 2

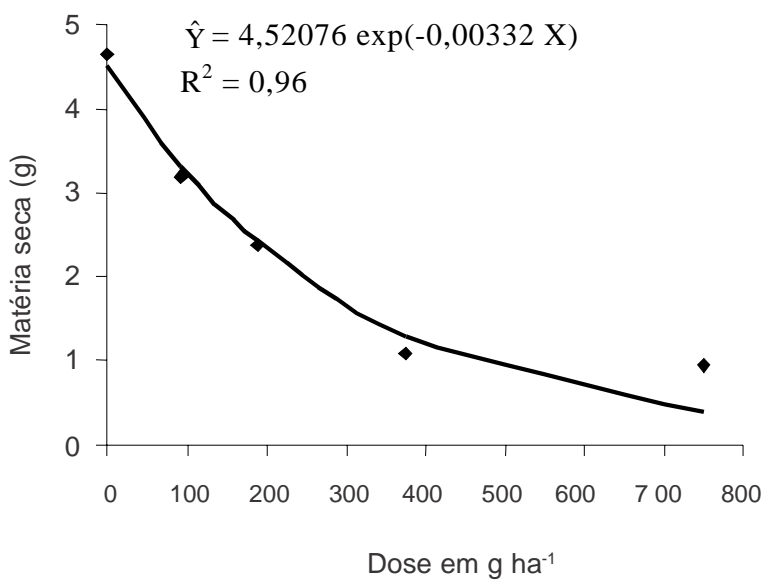

CLONE 4

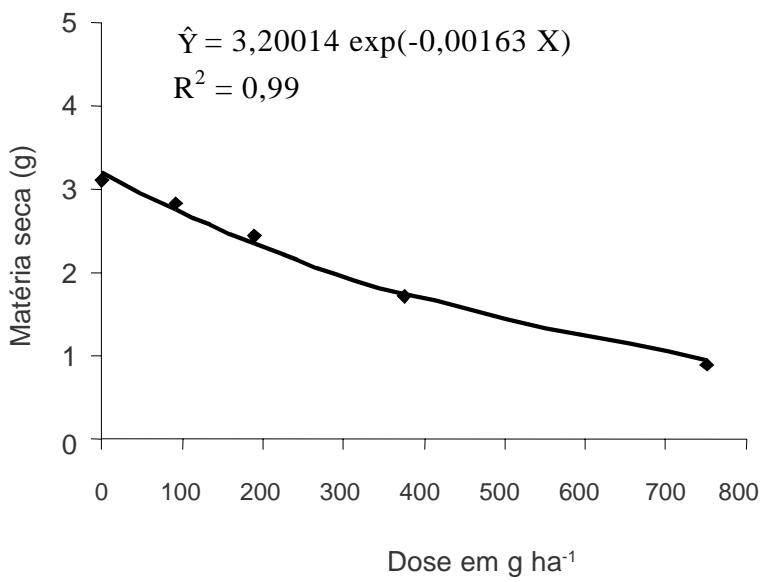

Figura 3 - Matéria seca da parte aérea de plantas de sorgo aos 25 dias após semeadura na porção equivalente à profundidade de 15 a $30 \mathrm{~cm}$, nos vasos com plantas de eucalipto que receberam aplicação foliar de doses de imazapyr aos sete meses após o plantio e foram cortadas 30 dias depois da aplicação do herbicida.

Outros autores relatam o efeito de moléculas herbicidas exsudadas, por plantas tratadas, e seus efeitos em culturas subseqüentes. Rodrigues et al. (1982), trabalhando com exsudação do ${ }^{14} \mathrm{C}$-glyphosate, observaram que plantas de trigo exsudaram o herbicida pelas raízes e que plantas de milho absorveram ${ }^{14} \mathrm{C}$-glyphosate do solo, sendo a molécula herbicida translocada para todas as partes da planta de milho.

As plantas de sorgo apresentaram valores de $I_{50}$ semelhantes entre si (Tabela 2) tanto para os diferentes clones de eucalipto como para as duas profundidades avaliadas, indicando que não houve diferença de exsudação entre os clones e entre as duas profundidades.

De acordo com os resultados, conclui-se que os quatro clones estudados exsudam imazapyr pelo sistema radicular e que a menor dose de imazapyr aplicada, $93 \mathrm{~g} \mathrm{ha}^{-1}$ do i.a., não permitiu a rebrota dos quatro clones de eucalipto. Os sintomas de toxicidade do sorgo, cultivado após o corte das plantas de eucalipto, acentuaram-se com o aumento das doses de imazapyr aplicado sobre os clones de eucalipto e seus efeitos foram semelhantes nas duas profundidades analisadas: 0 a 15 e 15 a $30 \mathrm{~cm}$. 
Tabela 2 - Valores de $\mathrm{I}_{50}$, em g ha ${ }^{-1}$ do i.a.de imazapyr, com base na produção de matéria seca da parte aérea de plantas de sorgo, 25 dias após semeadura, nas diferentes profundidades do perfil do solo cultivado com diferentes clones de eucalipto, 30 dias após a aplicação do herbicida

\begin{tabular}{|c|c|c|}
\hline \multirow{2}{*}{ Clone } & \multicolumn{2}{|c|}{$\mathrm{I}_{50}$} \\
\cline { 2 - 3 } & \multicolumn{2}{|c|}{ Profundidade } \\
\cline { 2 - 3 } & $0 \mathrm{a} 15 \mathrm{~cm}$ & $15 \mathrm{a} 30 \mathrm{~cm}$ \\
\hline 1 & 513,4 & 630,1 \\
\hline 2 & 366,7 & 208,8 \\
\hline 3 & 572,8 & 339,8 \\
\hline 4 & 316,5 & 425,2 \\
\hline
\end{tabular}

\section{AGRADECIMENTOS}

A David Fernandes e CENIBRA S.A., pelo apoio e fornecimento dos clones de eucalipto; e ao CNPq, pela bolsa de iniciação científica.

\section{LITERATURA CITADA}

COUPLAND, D.; CASELEY, J. C. Presence of ${ }^{14} \mathrm{C}$ activity in root exsudates and guttation fluid from Agropyron repens treated with ${ }^{14} \mathrm{C}$-labelled glyphosate. New Phytol., v. 83, n. 1 , p. 17-22, 1979.

FITES, R. C.; SLIFE, F. W.; HANSON, J. B. Translocation and metabolism of radioactive 2,4-D in jimsonweed. Weeds, v. 12 , n. 3 , p. $180-183,1964$.

GUBBIGA, N. G.; WORSHAM, A. D.; CORBIN, F. T. Root/ rhizome exudation of nicosulfuron from treated johnsongrass (Sorghum halepense) and possible implications for corn (Zea mays). Weed Sci., v. 44, n. 3, p. 455-460, 1996.

BRASIL. Ministério da Ciência e Tecnologia (MCT), Projeto Genolyptus. Disponível em: <http://www.mct.gov.br/ especial/genolyptus4.htm>, Acesso em: 10 jul. 2005.

RODRIGUES, J. J. V.; WORSHAM, A. D.; CORBIN, F. T. Exudation of glyphosate from wheat (Triticum aestivum) plants and its effects on interplanted corn (Zea mays) and soybeans (Glycine max). Weed Sci., v. 30, p. 316-320, 1982.
RODRIGUES, B. N.; ALMEIDA, F. S. Guia de herbicidas. 5.ed. Londrina: 2005. 592 p.

SOCIEDADE BRASILEIRA DE SILVICULTURA - SBS. Dados estatísticos sobre a produção nacional de eucalipto. <http://www.ipef.br/sbs/estatisticas>. Acesso em: 12 jun. 2003.

SHANER, D. L.; REIDER, M. L. Physiological responses of corn (Zea mays) to AC 243,997 in combination with valine, leucine and isoleucine. Pestice Biochem. Physiol., v. 25, p. 248-257, 1986.

SHANER, D. L. Factors affecting soil and foliar bioavailability of the imidazolinone herbicide. New Jersey: American Cyanamid Company, 1989. 24 p.

SILVA, A. P. Estudo do comportamento da brotação de Eucalyptus grandis W. Hill ex. Maidem a nível de progênies de polinização livre. Piracicaba: 1983. $77 \mathrm{p}$.

SILVA, C. M. M. et al. Root exudation of imazapyr by eucalypt, cultivated in soil. Planta Daninha, v. 22, n. 1, p. 109-116, 2004a.

SILVA, C. M. M. et al. Tolerance of eucalypt (Eucalyptus spp.) seedlings to imazapyr in nutritive solution. Planta Daninha, v. 22, n. 4, p. 597-606, 2004b.

SILVA, W. Tolerância de Eucalyptus spp. a herbicidas e a eficiência desses produtos no controle de plantas daninhas. 1993. 83 f. Dissertação (Mestrado em Fitotecnia) Universidade Federal de Viçosa, Viçosa, 1993.

TUCKER, T. A.; LANGELAND, K. A.; CORBIN, F. T. Absorption and translocation of ${ }^{14} \mathrm{C}$-Imazapyr and ${ }^{14} \mathrm{C}$ Glyphosate in alligatorweed Alternanthera philoxeroides. Weed Technol., v. 8, n. 1, p. 32-36, 1994.

ZONTA, E. P.; MACHADO, A. A. SANEST - Sistema de análise estatística para microcomputadores. Pelotas: Universidade Federal de Pelotas, 1984. 75 p. 